\title{
“O DESENHO É UMA PRONÚNCIA": PAULA REGO E AGUSTINA BESSA-LUÍS
}

\author{
Mariana Andrade da Cruz \\ Universidade Federal Fluminense
}

Resumo: O objetivo do presente trabalho é fazer uma análise do livro As meninas, no qual a romancista portuguesa Agustina Bessa-Luís fala sobre vida e obra da pintora Paula Rego, também portuguesa. Embora possua contornos biográficos, focalizando especialmente a infância de Rego e o relacionamento que manteve com Victor Willing, o texto trará reflexões variadas sobre a natureza do fazer artístico em si. Cremos que, ao lê-lo, podemos considerá-lo não só como um relato de apreciação crítica da fortuna artística de Rego, mas também como um livro cujo valor reside em si próprio. Ao apresentar a biografia da pintora, Bessa-Luís encontra pontos de contato com sua própria vivência, e usa-os como ponto de partida para tecer inúmeras reflexões de ordem metalinguística, bem como acerca das relações entre texto e tela. Considerando isso, pretendemos mostrar como o livro muitas vezes indicia um diálogo interartes, além de evidenciar pontos de contato entre a escrita de Bessa-Luís e as imagens que permeiam o volume.

Palavras-chave: Agustina Bessa-Luís. Paula Rego. As meninas.

\section{Um texto de natureza híbrida}

Desde o princípio, pedimos licença à escritora contemporânea portuguesa Agustina Bessa-Luís para roubar de seu livro "As meninas" - texto de gênero híbrido, mescla de biografia e ficção, em que ela se debruça por sobre vida e obra da pintora Paula Rego, igualmente portuguesa e contemporânea - a frase que aqui utilizamos à guisa de título: “o desenho é uma pronúncia" (REGO; BESSA-LUÍS, 2008, p. 17). Ao usar o aforismo em seu livro, Bessa-Luís pretendia evidenciar uma relação entre a vivência e a representação, de modo que a imagem sempre falaria da própria e legítima experiência do artista que a engendrou - é o que demonstra a sequência posterior à máxima, em que a autora discorre:

Onde nascemos, que influência tiveram em nós as primeiras vozes que ouvimos, as corruptelas, o som e a intenção que ele transmite, se de agressão ou carinho, tudo

\section{Esta obra está licenciada sob uma Creative Commons - Atribuição 4.0}

\footnotetext{
* Doutoranda em Literatura Comparada pela Universidade Federal Fluminense (UFF), como bolsista CNPq. Mestre em Estudos de Literatura, Subárea Literatura Portuguesa e Literaturas Africanas de Língua Portuguesa, como bolsista CAPES, pela mesma instituição (2012). Dedica-se a estudar, no momento, relações interartes verificáveis na ficção portuguesa contemporânea, especialmente a engendrada por António Lobo Antunes. Email: < mariana.and@hotmail.com>.
} 
aparece no desenho da escrita. Não é em vão que os grafologistas se debruçam sobre a caligrafia das pessoas para interpretar a sua mente. A fala é igualmente feita pelos hábitos da infância, está propensa aos mesmos erros de que só se corrige à custa de dolorosos efeitos. O desenho, como a fala, traduz essa experiência inocente da primeira idade. (REGO; BESSA-LUÍS, 2008, p. 17-18)

O postulado de Agustina é perfeitamente cabível em uma proposta de elaboração textual na qual se observam e avaliam detidamente alguns quadros da carreira de Paula Rego, encontrando como principal fio condutor entre eles a presença feminina, forte e intensa mesmo nas suas frequentes representações em fases mais pueris. Ao longo desta - suposta análise, flashes da vida pessoal de Rego vão pouco a pouco se espraiando, concentrando-se especialmente em sua infância e nos fatos referentes a seu relacionamento com Vic Willing. Em verdade, é difícil distinguir o propósito exato de um texto que tece uma espécie de biografia ficcionalizada, distante de uma ordem cronológica ou de qualquer outra espécie que não seja aquela imposta pela própria apreciação dos quadros, imiscuída por comentários de Bessa-Luís sobre assuntos variados, bem como por reflexões de natureza metalinguística. Em certa medida, o perfil textual tecido por Bessa-Luís aproxima-se daquele enredado por Alberto Manguel em seu livro Lendo imagens, no qual cada capítulo é dedicado à obra de um artista visual, seja este pintor, escultor, fotógrafo ou até mesmo arquiteto. É também Manguel quem nos oferece o subsídio teórico ao qual a obra "As meninas" se alinha, ao dizer, no capítulo introdutório de seu volume, que

\footnotetext{
Leituras críticas acompanham imagens desde o início dos tempos, mas nunca efetivamente copiam, substituem ou assimilam as imagens. "Não explicamos as imagens", comentou com sagacidade o historiador da arte Michel Baxandall, “explicamos comentários a respeito de imagens.". Se o mundo revelado em uma obra de arte permanece sempre fora do âmbito dessa obra, a obra de arte permanece sempre fora do âmbito de sua apreciação crítica. [...]

Para o bem ou para o mal, toda obra de arte é acompanhada por sua apreciação crítica, a qual, por sua vez, dá origens a outras apreciações críticas. Algumas destas transformam-se, elas mesmas, em obras de arte, por seus próprios méritos. (MANGUEL, 2011, p. 29-30, grifo nosso)
}

Por outro lado, o aforismo de Agustina parece-nos ganhar novas facetas, à medida que o aplicamos à realidade esboçada ao longo das cento e vinte e quatro páginas de $A s$ meninas. Escritora e pintora se unem por um elo que passa pelo elemento afetivo e desemboca na correspondência entre os trabalhos de uma e de outra, de maneira que a sentença ganha nova significação. Vê-se tantos pontos de contato entre os trabalhos mútuos - estes, derivados de vidas com características similares -, elos inclusive sugeridos pela própria Bessa-Luís em diferentes passagens, como, por exemplo, ao comentar, em um diálogo simulado com Rego nas últimas páginas do livro, que "Eu também gostava de me fantasiar em sonhos, e era uma 
vez esta ou aquela heroína. Não no gênero santa, mas até um bocado pecadora." (REGO; BESSA-LUÍS, 2008, p. 110), que a relação interartes já se estabelece como inevitável. Nesse ínterim, o imagético converte-se em léxico e vice-versa, e a frase "o desenho é uma pronúncia" ganha contornos de intermidialidade, à semelhança do "ut pictura poesis" de Horácio.

Em primeiro lugar, a fim de se estabelecer tal paridade, note-se que a autoria deste livro é dividida, desde a sua capa, que elenca os nomes de pintora e escritora com as mesmas fonte e tamanho, sem sugerir a superposição do trabalho ora de uma, ora de outra. As assinaturas de ambas estão dispostas na página final do livro, como se autografassem a obra ali engendrada. Valiosas são as imagens, tanto quanto o texto de Bessa-Luís, e a costura existente entre ambos permite que se leia imagem e palavra, em signos identificáveis e comuns. As páginas são pontuadas por quadros de Rego, dispostos aproximadamente em consonância com as referências feitas por Bessa-Luís, que dinamizam o espaço de análise e carregam a missão do livro - uma biografia encomendada - para um campo aprazível, que muito se distancia de uma escrita marcada pela obrigatoriedade.

Com efeito, pensar a "desconcertante Agustina", para usar as famosas palavras de Eduardo Lourenço, bem como as interseções possíveis entre a sua escrita e as facetas perversas das "pequenas assassinas" que povoam as pinturas de Paula Rego, significa, mais do que tecer considerações de cunho acadêmico, adentrar um espaço de intimidade que vai da artista literária à plástica. Os elementos comuns à infância das duas - a casa povoada por mulheres, a quinta e sua natureza essencialmente portuguesa - unem-nas intrinsecamente, e essa proximidade é referida por Bessa-Luís já nas primeiras páginas do livro, em que a autora menciona o seu primeiro contato com a artista, em 1992, quando esta última já era internacionalmente conhecida e, devido aos múltiplos afazeres decorrentes desse recente descobrimento, recusou um convite para produzir telas destinadas ao teatro que, na ocasião, Agustina comandava.

Ouvi a Paula Rego ao telefone e a voz dela não me agradou. Tinha o mesmo tom enervante e desprendido da Vieira da Silva quando falava das coisas de Portugal. Uma mistura de indiferença e calorosa maneira de receber, como se recebe uma visita, quase uma estranha. Eu perguntei-lhe se queria pintar duas grandes telas, ou quatro, para o salão nobre do Teatro D. Maria onde eu era diretora, e Paula respondeu-me com um prazer que tinha que ver com a sua glória nascente ou já desfrutada em pleno. Um prazer de recusar uma encomenda, por tentadora que ela fosse. Indicou-me outra pessoa para pintar os quadros, e isso impediu que eu quisesse vencer toda a série de obstáculos que se levantavam à minha frente: não tanto a peregrinação de porta a porta, em vista dos patrocinadores, mas sobretudo a mesquinha e surda altercação que se forma em volta dos sonhos de alguém. Eu desisti. Era em 1992, e Paula Rego gozava duma celebridade que a exposição $A$ 
menina e o cão, de 1987, na Edward Totah Gallery, no West End, lhe granjeara. (REGO; BESSA-LUÍS, 2008, p. 9-10)

A impossibilidade de travar maior contato, então, com "essa vida audaciosa e simples com a qual me aparentava" (REGO; BESSA-LUÍS, 2008, p. 10-11) permite que se abra uma nova via, a da aproximação na e pela arte, viável por intermédio do gesto de levar a mão à pena e, por extensão, encontrar um caminho iniciático que aproxima Bessa-Luís e Rego não apenas por suas produções, mas antes por uma identificação que se sugere mútua, embora leiamos a versão de apenas uma integrante do par.

\begin{abstract}
Era como uma pessoa de família que se tinha esquecido de mandar notícias durante um itinerário cheio de peripécias que resumiam um gigantesco trabalho. Quando pego na pena para escrever sobre Paula Rego, faço-o como se reatasse um antigo encontro. Desde a infância.

Lentamente, desdobro as pregas dessa vida de menina e em muitos detalhes eu estou lá. Na solidão da quinta, na fantástica e humilde marcha doméstica a que não faltam clarins de vozes, bater de portas, tambores de chuvas e fervuras, sangue e água nas pias, os olhos moribundos das galinhas depenadas com água quente. A brutalidade nem sequer envergonhada dos predadores, os comedores de jantares rituais, o afeto repartido entre as crianças, os sabores, os animais. Um mundo perverso e encantado que as histórias de fadas e princesas trazem no ventre e que vão fazer a lauta obra dum artista, se ela se escapa pelas malhas da casa materna e se evade para o mundo. $\mathrm{O}$ mundo artista é um prolongamento da infância, dos seus medos e dos seus gritos penetrantes como o que os pavões soltam num parque deserto. Um parque arruinado, não um jardim francês, geométrico e letal. (REGO; BESSA-LUÍS, 2008, p. 11-12)
\end{abstract}

Quando fala dessa espécie de infância prolongada que é a obra do artista, Agustina não fala tão somente das telas de Rego, mas também de si própria, participante que foi de um similar universo infantil, compartilhando as duas artistas elementos de contiguidade em seus primeiros anos. Esse talvez seja o núcleo daquilo que se nos afigura como, enfim, o possível mote do livro: interpretar e recontar - ou até mesmo, em certa medida, ficcionalizar - a biografia de Paula Rego, de maneira que a gênese de muitas de suas obras explicar-se-ia por experiências pessoais, a maioria particularmente ligada a memórias precoces. Ao comentar o trabalho dessa artista, Bessa-Luís entra também em contato com suas próprias memórias, recapitulando etapas de seu processo criativo ficcional.

\title{
As meninas e suas duras mãos
}

A capa do livro apresenta um quadro de Paula Rego, A familia (1988). A imagem, centralizada, posiciona-se abaixo do título do livro e acima do nome das artistas. Ela também se repete, no mesmo tamanho, nas primeiras paginações internas, antecipando-se ao início do texto de Bessa-Luís propriamente dito, que compõe a parte escrita do livro. Nessa aparição iniciática, posterior à capa, o quadro - que domina, sozinho, uma página, quadrado colorido dentro do retângulo branco - faz-se acompanhar por uma citação extraída do texto, e 
formatada de tal forma que ocupa, espacialmente, uma área similar àquela em que, na página ao lado, a imagem repousa. Em suma, introduzem a obra duas páginas vizinhas: uma, com o texto visual, outra, com o texto redigido; e a própria disposição gráfica desses elementos parece equiparar um e outro, sem ampliar nem a figura, nem o escrito; mostrando, por fim, como são correspondentes, como desenho e pronúncia estão (são) intrínsecos e equivalentes.

Figura 1: A família $(1988)^{1}$

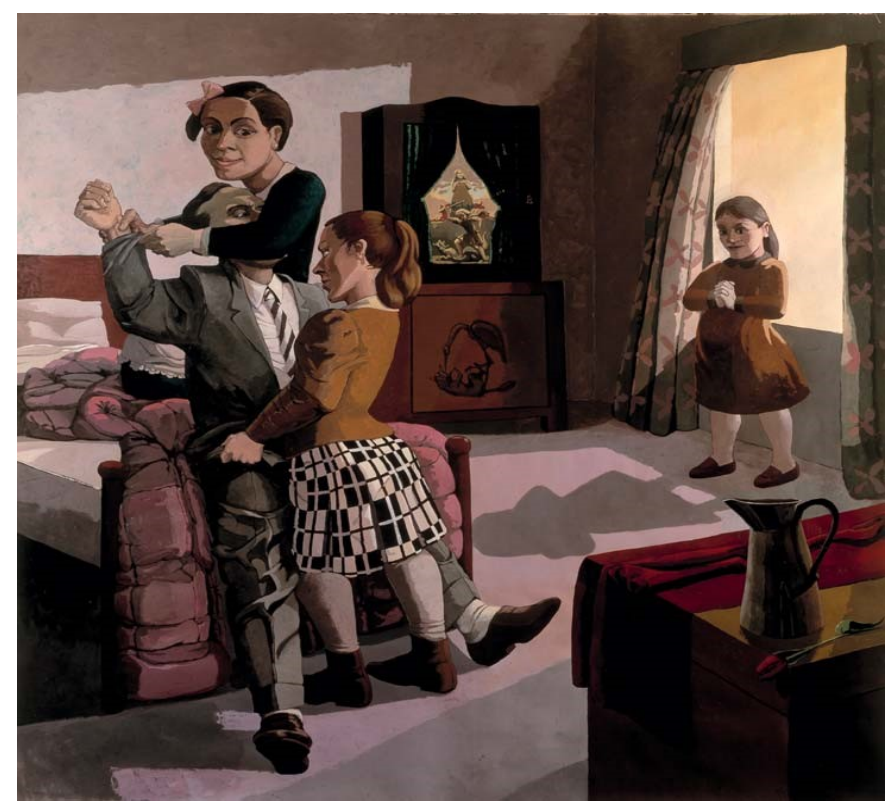

A citação de Agustina, vizinha ao quadro, é esta: "As meninas de todas as idades mostram-se na obra de Paula Rego. Têm o rosto das criadas que andavam pela casa da Ericeira e que tinham duras mãos capazes de assassinarem alguém.”. Para o leitor que tem, nessas páginas introdutórias, o seu primeiro contato com o livro, algumas impressões se delineiam: a conversa íntima que se estabelece entre imagem e texto, dentro da proposta interartes, e já se fincam impressões sobre escrita e pintura de meninas enigmáticas e desafiadoras.

A família aparecerá novamente no decorrer do livro, sendo representado, em tamanho maior, na página 35. A representação plural de figuras femininas possivelmente foi o mote para a escolha desta imagem como capa do livro - embora Rego tenha muitas outras obras em que há a presença de jovens, como Avestruzes dançarinas, também mencionada ao longo do texto e exposta na página sessenta e sete. Tais figuras, em $A$ família, são perversas, quase maquiavélicas. O ambiente é o de um quarto familiar. Ao fundo, no entalhamento de um

\footnotetext{
${ }^{1}$ Todas as imagens aqui presentes, à exceção da tela $A$ filha do polícia, que aparecerá mais adiante, foram extraídas do próprio livro.
} 
móvel, uma garça subjuga o animal que a caça. Acima do móvel, São Jorge atinge o dragão. E, no primeiro plano, duas das meninas dominam a figura masculina, enquanto uma terceira observa a cena, com ar prazenteiro, próxima à janela. Sua sombra estende-se sobre o chão, alcançando o pé da cama; suas mãos estão unidas, como se tramasse alguma coisa. $\mathrm{O}$ homem dominado está sentado, seu pulso direito segurado por uma das meninas, a mão crispada. Toda a sensação de intimidade e afetividade que poderia ser sugerida pelo título da obra se esvai ao vermos a tela - ou, no caso, sua representação nas páginas no livro. Ao aludir a essa pintura, Bessa-Luís tece o seguinte comentário:

\begin{abstract}
As Meninas de Paula Rego estão nessa situação. Em todas as atitudes anunciam servilismo, mas estão a comemorar um estado de alma que não é propriamente poético ou id́lico. Em 1988, data da morte do marido, Paula pinta A família. O homem está praticamente imobilizado como por efeito dum jogo corpo-a-corpo que parece a aplicação dum castigo. Um pouco afastada, uma menina olha a cena assustada e juntando as mãos de maneira talvez aflitiva. Num pequeno guignol vemos S. Jorge a matar o dragão, salvando Angélica de ser derrotada. Angélica, no cimo do seu rochedo, parece ter envelhecido enquanto esperava ser libertada. [...] Paula descreve $A$ familia como uma combinação de luta e heroicidade. A sombra da menina projecta-se no chão e parece assustá-la mais do que a cena que se desenrola no quarto. Trata-se de uma brincadeira ou dum crime? (REGO; BESSA-LUÍS, 2008, p. 33-34)
\end{abstract}

Vemos, aqui, que Agustina não faz uma mera leitura descritiva do quadro, ressaltando, ao contrário, a carga heroica camuflada por detrás de um servilismo pretenso, necessário diante da condição de ser mulher em um mundo que a relega apenas ao previamente estabelecido. A dominação da vontade masculina pelo feminino foi um elemento primordial para que Paula Rego vencesse os escrutínios estereotipados de uma família com raízes profundamente tradicionalistas. Ao se mudar para Londres, a pintora rompe geograficamente e, por extensão, ideologicamente - com um universo que a tentava atar, conforme Bessa-Luís descreve ao comentar outro quadro, Duas meninas com um cão, de 1987, em que vemos duas figuras a brincar com um animal, de maneira carinhosa, mas também em ameaça velada: um martelo se dispõe ao alcance de suas mãos, e seus olhares se voltam para o mesmo. As digressões de Bessa-Luís a partir de tal quadro são extensas; recortamos aqui alguns trechos, a fim de tentar transmitir o alcance de suas ideias:

As meninas com o cão. Embora Victor Willing achasse que Paula era especialmente dotada para o desenho, mais do que para a pintura (os ingleses sentem afinidades convencionais com o desenho), ela lançou-se na pintura com ardor. A fase pretensamente fálica exprime uma forma de indignação que atravessa uma aprendizagem do autor. [...] As trevas estão sempre presentes na obra de Paula Rego. Os jogos têm uma parte tenebrosa, e isso está presente nas brincadeiras com o cão. As meninas brincam com o cão como se fosse uma criança. Dão-lhe banho e dão-lhe de comer, barbeiam-no como se fosse um homem, o cão é um homem que se pretende servir e dominar pela servidão. $\mathrm{O}$ jogo consiste em fazer da servidão um 
poder. O cão, o que significa o cão? O guardião que ronda, grunhe, ameaça, previne da presença de estranhos, o homem, em suma? é preciso tratá-lo com respeito, darlhe mimos, pronunciar palavras de encantamento, como Abracadabra, vesti-lo, curálo, adormecê-lo até que ele fique inofensivo e seja possível vir pé-ante-pé e estrangulá-lo. As meninas com o cão fazem parte da revelação da obra, da tomada de posição perante a arte. [...]

As meninas e o Cão. É, manifestamente, uma alusão a um obstáculo. O cão representa o guarda que tem que ser transformado em brinquedo, que tem que ser reconhecido como tal, se não impede que o dom da menina se apresente. O pai disse: "Este não é um país para mulheres.". O tutor disse: "A escola de Arte só serve para que as raparigas fiquem grávidas.". Ela obedece, sai de casa, cede ao desejo dum homem e, na submissão, faz o seu trabalho, cresce em audácia, devora tudo em volta. Gosta de comer, mas isso não é de estranhar. É uma devoradora do que lhe é servido em pratos guarnecidos e prontos a ser saboreados. Mas Paula tem outros propósitos: gosta de destruir, de criar espaço para ela, de impor-se ao mundo. Para isso tem que ser obediente e aceitar o terror. (REGO; BESSA-LUÍS, 2008, p. 22-27)

Para crescer, avançar na arte, Rego tem de ser devoradora: por debaixo da carapuça de subserviência, tece seu próprio destino apesar das barreiras que encontra nas figuras do pai, do tutor, e até mesmo de Vic Willing, que acreditava que era seu dever investir no desenho, em vez da pintura. Seguindo suas próprias convicções, Paula enreda o obstáculo-cão, toda vez que este se apresenta a ela. Curiosamente, Agustina faz remissão ao uso necessário das "palavras de encantamento", como se fosse Rego uma nova Sherazade, e a história dita e redita ao longo das noites fosse a sua própria. Abracadabra é também o nome de um dos quadros da pintora, este, de 1986, e que - não por acaso - apresenta igualmente duas meninas a lidar com um cão, a entretê-lo: uma ergue as mãos diante da face cabisbaixa do animal, mas o curioso é que o olhar da jovem dirige-se para a sua companheira, posicionada por detrás do bicho, os braços estendidos para diante como se estivesse prestes a desferir um golpe.

Figura 2: Duas meninas com um cão (1987)

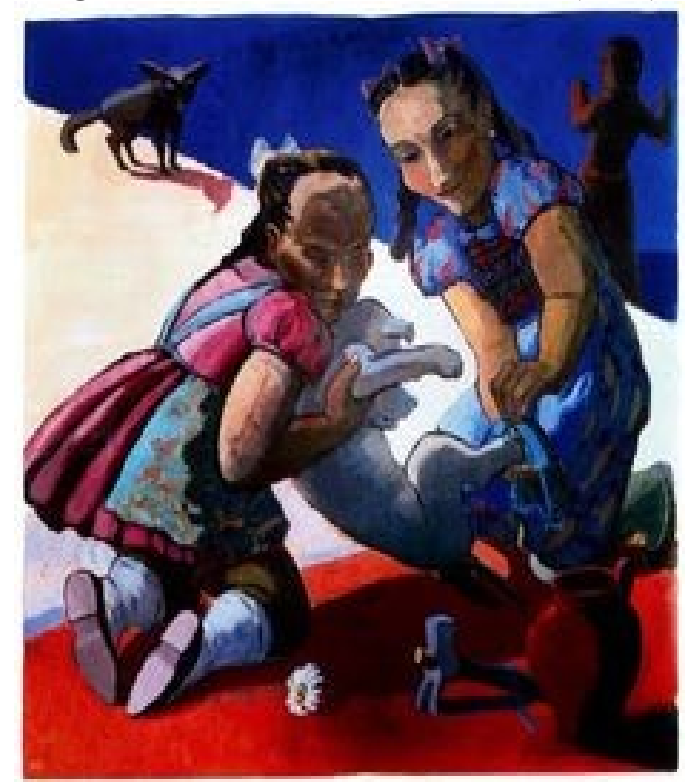




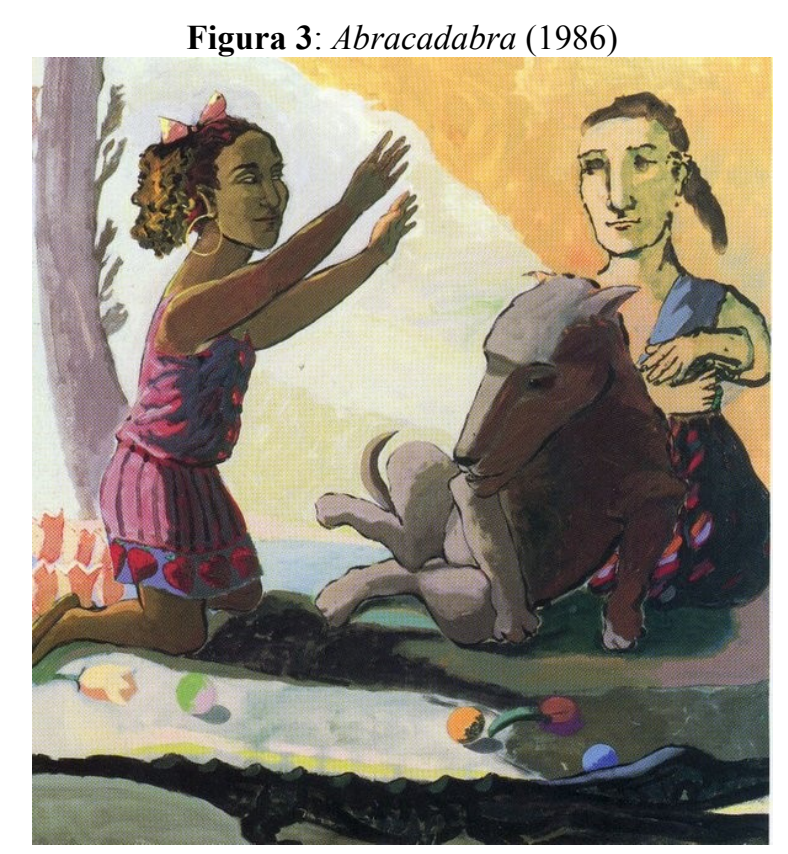

Sobre esse quadro, Bessa-Luís comenta: "As meninas exercem um efeito encantatório sobre o cão, como no caso de Abracadabra, ou procuram vesti-lo com roupas de criança enquanto a raposa observa de longe com os seus olhos astutos e indomável perfídia" (REGO; BESSA-LUÍS, 2008, p. 50). Note-se que, embora não citado nominalmente, Duas meninas com um cão encontra-se aqui descrito, e a relação entre as obras se estabelece não só pela presença de elementos comuns - notadamente, o animal e a dupla de moças -, mas sobretudo pela forte carga simbólica compartilhada por essas imagens, pela relação dúbia de jogo e desafio que se estabelece entre humano e bicho, que replica a postura incisiva e combatente que Paula Rego teve de adotar para firmar-se como artista.

Aqui, portanto, e mais uma vez, a arte explica-se pela experiência pessoal, tornandose o cão símbolo. São, no entanto, as meninas também símbolo. A fascinação pelo feminino guarda, similarmente, um elemento identitário e representativo. Muitas vezes, ao longo das páginas, Agustina reitera a infância como uma época contígua às duas artistas, que viveram em ambientes próximos e experimentaram acontecimentos de uma mesma natureza. Não seria equivocado, então, pensar que são ambas as artistas como as meninas do quadro: olhares furtivos e ao mesmo tempo desafiadores por sobre a realidade que as cerca, ousadia para se afirmarem como artistas apesar dos escrutínios amargamente conversadores. Bessa-Luís dirá que a menina permanece na mulher adulta, como um vestígio de utopia: “A utopia é um dado prodigioso para conhecer as mulheres. Umas e outras. É por isso que elas seguem os profetas de olhos fechados e mantêm, debaixo das rugas, um rosto de raparigas." (REGO; BESSALUÍS, 2008, p. 119). Ao comentar tal analogia, Anamaria Filizola menciona que: 
O processo biográfico agustiniano, que é sempre o produto de uma dialética vida e obra, adquire neste livro a expressividade mais bem acabada, a meu ver: parte dos quadros que não são autobiográficos e vê neles uma narrativa em que a protagonista é sempre Paula, uma Paula que é um espelho da própria Agustina, na vida e na obra. Talvez por isso, dos livros dedicados às pintoras, esse é o mais conseguido literariamente, porque nele o gênio de Agustina plenamente se revela [...].

O trabalho sobre Paula é delimitado: é relativo aos quadros em que aparecem As meninas. Eu diria que é um trabalho de interpretação desses quadros, mas neles está Paula, daí falar dela. Além da história que lê nos quadros como sendo a vida de Paula transmutada em imagens aleatórias, Agustina compõe uma poética que é a da criação das pinturas e coincide com a dos seus romances e também com a das suas biografias.

Paula Rego, como sujeito biográfico, assim como Vieira da Silva, provoca em Agustina um espelhismo, que, como já dito, é explicitado para o leitor e não interfere no resultado que é dado a ler: a biógrafa é o Outro biografado e é ela mesma. (FILIZOLA, 2009, p. 187-189).

Permanecendo crianças no íntimo, Agustina Bessa-Luís e Paula Rego alimentam suas elaborações com o material que lhes advém das recordações infantis. Assim é necessário fazer diante de um cenário que se afigura, muitas vezes, como hostil. No processo de observar as meninas que se sucedem nos quadros da pintora, a escritora acaba por localizar a ambas dentro de uma representação figurativa, que, de certa maneira, narra suas próprias histórias. $\mathrm{O}$ paradigma de uma biografia com contornos tradicionais rompe-se novamente, permitindo que o leitor contemple o espelhamento de que nos fala Filizola.

\section{Uma narrativa das imagens}

"Os quadros de Paula Rego são histórias", diz-nos de maneira enfática Bessa-Luís (2008, p. 36). Assim sendo, contam-nos tramas variadas, permitem que desvendemos e desfiemos hipóteses sobre as imagens que nos são expostas. Pode-se ler imagens, fabular, criar expectativas que vão além do impacto sensorial gerado pela tela e alcançam o status de ficcionalidade. Esse processo, inerente ao espectador, é o que Agustina emprega na composição do livro: o desenho, mais uma vez, torna-se pronúncia, escrita que domina as páginas do volume e tenta descortinar a vivência de cada uma das meninas. As informações que ela agrega para complementar sua leitura são múltiplas: mesclam seu conhecimento teórico às frequentes remissões da memória a que já aludimos aqui; buscam referências de ordem biográfica; aludem a pontos decisivos da carreira de Rego; citam referências literárias fortes para a pintora, em uma sugestão de ponte intertextual - os principais nomes seriam Edgar Allan Poe e Eça de Queirós. O percurso adotado pela autora delineia uma certa narrativa das imagens, em consonância com o discurso de Alberto Manguel:

Quando lemos imagens - de qualquer tipo, sejam pintadas, esculpidas, fotografadas, edificadas ou encenadas -, atribuímos a elas o caráter temporal da narrativa. Ampliamos o que é limitado por uma moldura para um antes e um depois e, por 
meio da arte de narrar histórias (sejam de amor ou de ódio), conferimos à imagem imutável uma vida infinita e inesgotável. [...]

E no entanto os elementos da nossa resposta, o vocabulário que empregamos para desentranhar a narrativa que uma imagem encerra (sejam os botes de Van Gogh ou o portal da Catedral de Chartres), são determinados não só pela iconografia mundial mas também por um amplo espectro de circunstâncias, sociais ou privadas, fortuitas ou obrigatórias. Construímos nossa narrativa por meio de ecos de outras narrativas, por meio da ilusão do autorreflexo, por meio do conhecimento técnico e histórico, por meio da fofoca, dos devaneios, dos preconceitos, da iluminação, dos escrúpulos, da ingenuidade, da compaixão, do engenho. (MANGUEL, 2011, p. 27-28)

Além dos quadros aos quais temos acesso explícito, por sua representação impressa nas páginas do livro, há aqueles a que se faz apenas alusão, cabendo ao leitor preencher as lacunas da identificação a partir de seu cabedal, de seu conhecimento acerca da produção da pintora. Talvez resida por detrás dessa prática o estímulo à busca por esses quadros até então obscuros, desconhecidos, que só se insinuam, aqui e ali, por entre o discurso ondulante de Agustina. Surpreende o leitor, por exemplo, encontrar, entre as divagações da autora, a seguinte colocação:

Nem tudo se pode interpretar, nem tudo tem que ter sentido. A filha do polícia que engraxa a bota diante da abertura da janela sem vidros e sem portadas, não quer dizer que ela alude à autoridade que é preciso amansar. Não é uma bota fálica. Porque é que uma bota há-de ser fálica e não aquilo que é? Uma bota alta que exerce fascinação numa criança porque é um tipo de calçado pouco usual. Eu lembro-me de ter tido verdadeiro encantamento perante as botas vermelhas das dançarinas ucranianas. E pela maneira como elas batiam no chão com os calcanhares, denunciando paixão e vigor. Era um ritual fascinante, mas não precisava de ter conotações fálicas. (REGO; BESSA-LUÍS, 2008, p. 65)

E, algumas páginas adiante (certamente exigindo do leitor um esforço de memória, a voltar as páginas, atarantado, com a vaga sensação de que aquela cena já se descortinara, antes, em algum momento):

A arte é um jogo de linguagem. A arte de Paula Rego é um jogo altamente complexo e que escapa à competência da crítica estética. $\mathrm{O}$ rosto está sempre na oposição da representação que lhe é imposta. É um rosto sério, sem nada de diáfano, de acordo com os pés duros e descalços. Entre ambos estão os vestidos e os gestos; gestos de submissão, como o da menina, filha do polícia, que engraxa a bota, ou a criada que penteia o rapaz que está de partida. A minúcia distrai a jovem mulher do sofrimento. (REGO; BESSA-LUÍS, 2008, p. 80, grifo nosso) 


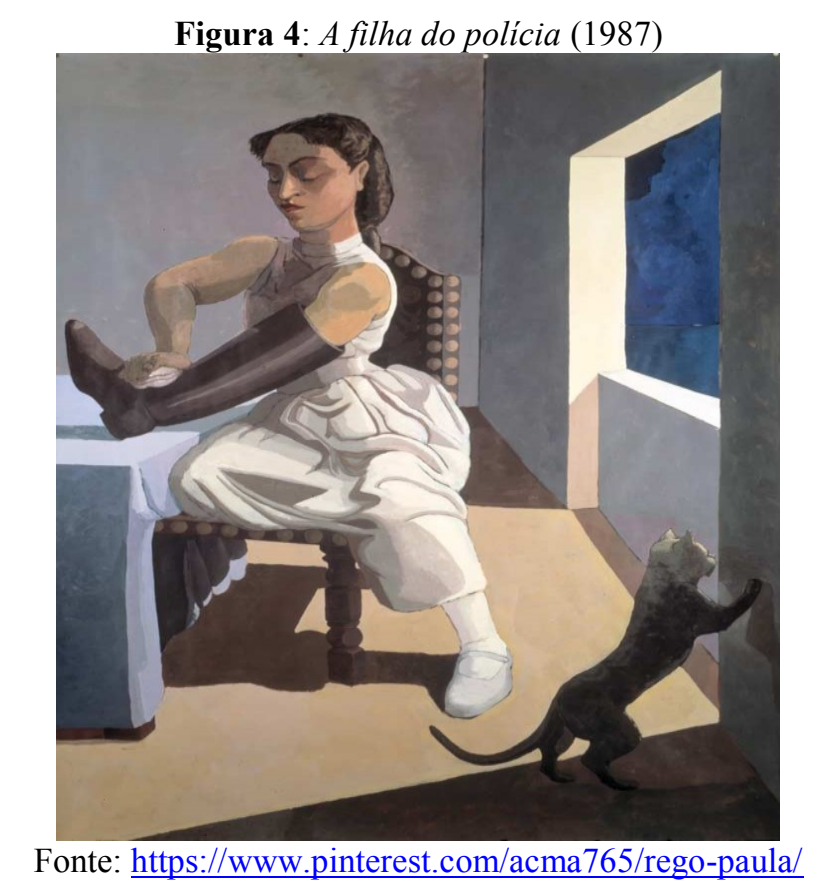

As duas ocorrências referem-se ao quadro A filha do polícia (1987), o qual, por sua vez, não foi um dos selecionados para compor o livro - muito possivelmente porque não é citado, nominalmente, por Agustina. Entretanto, essa não-presença nominal e figurativa não significa que a tela de Rego não esteja ali, presente por entre as recordações da autora sobre as dançarinas ucranianas, ou considerações acerca das tarefas cotidianas, de pequeno significado, mas de vulto tranquilizador, das jovens mulheres.

Sempre mantendo a presença das meninas como fio de Ariadne, o texto de BessaLuís percorre variados quadros, em sua maioria produzidos no final da década de 1980 e início dos anos 1990. São exibidas obras que, por sua temática, guardam uma relação ainda mais encravada com o universo infantil - O capitão Hook e o rapazinho perdido (1982), A terra do nunca (1992), explícitas referências ao conto de Peter Pan -; telas de inspiração bíblica - O sonho de José (1990) -; imagens da série de quadros que Rego produziu a partir do romance queirosiano O crime do padre Amaro - Anjo (1998), que exibe uma Amélia com espada em punho, rigidamente ameaçadora -; representações de cenas cotidianas - A capoeira (1998), No jardim (1986). As últimas páginas do livro são, por fim, reservam a apresentação do Jardim de Crivelli (1990), que é, para Agustina, a bíblia da vida de Paula Rego, "em que todas as histórias tenham o seu lugar, tanto as divinas como as profanas" (REGO; BESSALUÍS, 2008, p. 103).

Durante a apresentação dos painéis esquerdo e direito do Jardim, surge um diálogo fictício entre escritora e pintora. Nele, Agustina revela: "Pareço divertida, mas estou disposta a arrancar tudo que sirva para o que escrevo.” (2008, p. 105). Decerto, a autora extraiu das 
telas o máximo que podia para a construção deste As meninas (e de quantos mais outros textos, anteriores e posteriores?). Entretanto, o dado mais valioso do livro talvez seja o de que o leitor pode, perfeitamente, acrescentar novos significados, particulares, tanto aos quadros quanto à redação. Afinal, conforme diz Silvina Rodrigues Lopes em longo trabalho sobre a ficção de Bessa-Luís, “é esse também mais um dos motivos do inacabamento de qualquer obra, a necessidade de continuar a receber, independentemente do momento em que é escrita, a nossa projeção da realidade, renovando as suas respostas em função dela.” (LOPES, 1992, p. 15). Logo após, Lopes diz que é nesse processo que reside o "intercâmbio entre o efêmero e o eterno". Conforme essa instrução, a leitura jamais se esgota. Como leitores, sigamos, pois.

\section{Referências}

FILIZOLA, Anamaria. É a Paula que está a dizer isto ou sou eu?: As meninas, de Agustina Bessa-Luís e Paula Rego. Revista Literatura em Debate, Frederico Westphalen - RS, v. 4, n. 5, p. 180-194, jul.-dez., 2009.

LOPES, Silvina Rodrigues. Agustina Bessa-Luis: as hipóteses do romance. Rio Tinto: Edições Asa, 1992.

MANGUEL, Alberto. Lendo imagens: uma história de amor e ódio. São Paulo: Companhia das Letras, 2011

REGO, Paula; BESSA-LUÍS, Agustina. As meninas. Lisboa: Guerra e Paz, 2008.

[Recebido em fevereiro de 2016 e aceito para publicação em abril de 2016]

"The drawing is a pronunciation": Paula Rego and Agustina Bessa-Luís

Abstract: The aim of this text is to analise The Girls, book in which portuguese novelist Agustina Bessa-Luís concerns the compatriot painter Paula Rego's life and work. In spite of its biographic contours, with special focus on Rego's childhood and her relationship with Victor Willing, the text brings various reflexions about the nature of the artistic job itself. It is believed that, by reading the novel, it is possible to consider it not only as a critic appreciation report of Rego's artistic fortune, but also as a book which value indwells in itself. By introducing the painter's biography, Bessa-Luis finds connections with her own experience, and use them as starting points to weave a great number of metalinguistic reflexions, as well as thoughts about the relation between text and canvas. Considering that, it is intended to demonstrate how the book accuses an interartistical dialog, also demonstrating connecting points between Bessa-Luis writing and the images that permeates the novel.

Keywords: Agustina Bessa-Luis. Paula Rego. The girls.

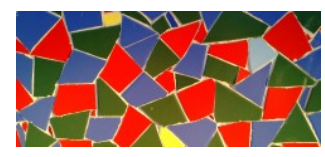

